\title{
Influence of process parameters on properties of Nanostructured Lipid Carriers (NLC) formulation*
}

\author{
Elwira Lasoń ${ }^{凶}$, Elżbieta Sikora and Jan Ogonowski \\ Institute of Organic Chemistry and Technology, Cracow University of Technology, Kraków, Poland
}

\begin{abstract}
Nanostructured lipid carriers (NLC) are stable colloidal formulations with notable advantages for drug delivery systems. Thanks to their physicochemical stability, biocompatibility, biodegradability and controlled drug release, they have received increasing attention for the last several years. The aim of the study was to prepare and characterize nanostructured lipid carriers (NLC). Both, the effect of the process parameters and the effect of the preemulsion composition on the NLC properties were investigated. In the work, different type of surfactants (i.e. decyl glucoside, Poloxamer188, Tween 80 , sodium cholate) and their combinations were used to stabilize NLC dispersions. Moreover, several kinds of solid lipids (modified beeswax, gliceryl behenate, cetyl palmitate and berry wax) and liquid lipids (caprilic/capric triglyceride and decyl oleate) were applied. An ultrasonication method using a probe type sonicator was used to obtain NLC, and the time and energy of the process were modified throuhout. The physicochemical properties of the formulations, such as particle size, size distribution, polidispersity index were studied using the dynamic light scattering (DLS) method. The electrophoretic mobility of obtained particles was also measured, using the Zetasizer Nano ZS Malvern Instrument based on the Laser Doppler Velocimetry (LDV) technique. Knowing the value of electrophoretic mobility of particles for given conditions, the zeta potential was determined. The obtained results showed that the process parameters and the composition of the preemulsion had significant impact on the nanoparticles structure. The optimal formulations size ranged between 60 and $80 \mathrm{~nm}$, and the value of their zeta potential was up to $-30 \mathrm{mV}$. The stability of these systems was further confirmed by macroscopic observation.
\end{abstract}

Key words: nanostructured lipid carriers, NLC, liquid lipids, solid lipids, ultrasonication

Received: 14 October, 2013; revised: 04 December, 2013; accepted: 04 December, 2013; available on-line: 29 December, 2013

\section{INTRODUCTION}

Nanosized drug delivery systems have been intensively investigated in recent years (Saraf et al., 2011a; Saraf et al., 2011b). They can generally be divided into two groups: polymeric and lipidic systems. The number of products containing polymeric nanoparticles on the market, is restricted due to the toxicity of polymers and a lack of proper large-scale production techniques. That is why a great deal of interest has been focused on lipidbased carriers represented by solid lipid nanoparticles
(SLN) and nanostructured lipid carriers (NLC) (Sawant et al., 2008; Chen et al., 2010). Both of them can be widely applied to deliver active ingredients through oral, parenteral and topical routes (Almeida et al., 2007; Müller et al., 2007; Schafer-Korting et al., 2007).

SLN are prepared by replacing the liquid lipid (oil) of an oil in water $(\mathrm{o} / \mathrm{w})$ emulsion with a solid lipid or a blend of solid lipids. These lipids consist of biodegradable, physiological lipids or lipidic substances and stabilizers, which are generally recognized as safe (GRAS) (Das et al., 2011). However, there are some potential limitations concerning SLN's structure. During storage, they can transform to the low energy, more ordered $\beta$ modification. Due to their high degree of order, the number of imperfections in the crystal lattice is reduced, leading to active ingredient expulsion within a short period of time (Westesen et al., 1997). NLC were introduced to overcome the potential difficulties with the SLN's structure. They are composed of the blend of solid and liquid lipids (oils), which induces a melting point depression compared to the pure solid lipid, but the particles are still solid at room and body temperature. The incorporation of liquid lipids in those structures inhibits the crystallization process by mixing "spatially" different molecules. This results in significant differences in the particle matrix structure. NLC possess many imperfections, which supports an increase in active loading capacity and a decrease in or avoidance of active substance expulsion during storage (Müller et al., 2002a; Radtke et al., 2007; Hu et al., 2006).

Lipid nanoparticles can be produced by various traditional dispersion techniques. Considering industrial needs, high pressure homogenization is conventionally, the most preferred and popular method for the preparation of these nanocarriers (Müller et al., 1995; Pardeike et al., 2009). However, ultrasonic dispersion may offer an appropriate alternative for the laboratory scale, due to a relatively low cost of the apparatus and, what is also very important, a rapid nature of production (Schwarz et al., 2012).

Most of the reports about lipid nanoparticles focus on certain bioactive-loaded carriers. Entrapment efficiency, loading capacity, release profile and stability of active in these formulas are investigated. As for drug-free NLC systems, the effect of various surfactants (Han et al., 2008; Kovacevic et al., 2011) and influence of different lipids on the formulation (Zheng et al., 2013) have been

e-mail: elason@chemia.pk.edu.pl

*Presented at the 5th Central European Congress of Life Sciences „EUROBIOTECH 2013", Kraków, Poland.

Abbreviations: NLC, Nanostructured lipid carriers 
Table 1. Formulation of NLC systems (\%wt.)

Composition of the lipid nanoparticle dispersions produced with six surfactants and their combination. The particle matrix consisted of Apifil as solid lipid and Myritol as liquid lipid with changed ratios is from 1 to 15 . Formulation 16 was prepared with different liquid lipid and 17-19 with different solid lipid.

\begin{tabular}{|c|c|c|c|c|c|c|c|c|c|}
\hline No & $\begin{array}{c}\text { Apifil }(\%) \text { solid } \\
\text { lipid }\end{array}$ & $\begin{array}{c}\text { Myritol } 312(\%) \\
\text { liquid lipid }\end{array}$ & $\begin{array}{c}\text { PlantaCare } \\
\text { 2000UP (\%) }\end{array}$ & $\begin{array}{l}\text { Poloxam- } \\
\text { er188 }(\%)\end{array}$ & $\begin{array}{c}\text { TegoCare } \\
\text { CG-90 (\%) }\end{array}$ & $\begin{array}{c}\text { Crodesta } \\
\text { SL40LQ (\%) }\end{array}$ & $\begin{array}{c}\text { Tween } 80 \\
(\%)\end{array}$ & $\begin{array}{c}\text { Sodium } \\
\text { cholate }(\%)\end{array}$ & $\begin{array}{c}\text { Water } \\
(\%)\end{array}$ \\
\hline 1 & 7 & 3 & 4 & - & - & - & - & - & 86 \\
\hline 2 & 10 & 5 & 4 & - & - & - & - & - & 86 \\
\hline 3 & - & 10 & 4 & - & - & - & - & - & 86 \\
\hline 4 & 9 & 1 & 4 & - & - & - & - & - & 86 \\
\hline 5 & 7 & 3 & 2.5 & 1.5 & - & - & - & - & 86 \\
\hline 6 & 7 & 3 & - & 4 & - & - & - & - & 86 \\
\hline 7 & 7 & 3 & 2.5 & - & 1.5 & - & - & - & 86 \\
\hline 8 & 7 & 3 & - & - & 4 & - & - & - & 86 \\
\hline 9 & 7 & 3 & 2.5 & - & - & 1.5 & - & - & 86 \\
\hline 10 & 7 & 3 & - & - & - & 4 & - & - & 86 \\
\hline 11 & 7 & 3 & - & - & 2 & - & - & - & 86 \\
\hline 12 & 7 & 3 & 2.5 & - & - & - & 1.5 & - & 86 \\
\hline 13 & 7 & 3 & - & - & - & - & 4 & - & 86 \\
\hline 14 & 7 & 3 & 2.5 & - & - & - & - & 1.5 & 86 \\
\hline 15 & 7 & 3 & - & - & - & - & - & 4 & 86 \\
\hline 16 & 7 & 3 Cetiol V & 4 & - & - & - & - & - & 86 \\
\hline 17 & 7 Compritol & 3 & 4 & - & - & - & - & - & 86 \\
\hline 18 & 7 Cutina Cp & 3 & 4 & - & - & - & - & - & 86 \\
\hline 19 & 7 Berrywax & 3 & 4 & - & - & & & & 86 \\
\hline
\end{tabular}

also studied. The validity of such research could provide useful information for further application.

In this study, the drug-free NLC were prepared through the ultrasonication method. The effect of composition (different kind of surfactants, solid and liquid lipids) and parameters of the emulsification process on NLC formation and their properties were investigated. The physicochemical features of the obtained formulations were analyzed using the dynamic light scattering (DLS) electron microscope working in transmission mode (TEM).

\section{MATERIALS AND METHODS}

Materials. As solid lipids, Apifil ${ }^{\circledR}$ (modified beeswax) and Compritol ${ }^{\circledR}$ 888ATO (gliceryl behenate from Gattefossé GmbH, Germany), Cutina ${ }^{\circledR}$ CP (cetyl palmitate from BASF, Germany) and Berry Wax (KahlWax, Germany) were used. As liquid lipids, Myritol ${ }^{\circledR} 312$ (caprilic/capric triglyceride) and and Cetiol ${ }^{\circledR} \mathrm{V}$ (decyl oleate) from BASF, Germany, were applied. PlantaCare ${ }^{\circledR}$ 2000UP (decyl glucoside from BASF, Germany), Poloxamer 188 (Sigma-Aldrich, Poland), TegoCare CG-90 (Evonik Degussa International, Poland), Crodesta SL40LQ (Croda, Poland), Tween-80 (Caleo, Poland) and sodium cholate (Sigma-Aldrich, Poland) were chosen as surfactant. The distilled water was obtained by Millipore Direct-Q 5UV purification system.

Preparation of NLC. NLC were prepared bin the melt-emulsification and ultrasonication processe. A certain amount of solid lipid and liquid lipid was blended and melted at $80^{\circ} \mathrm{C}$, to form a homogenous and clear oil phase. The melted lipid phase was then dispersed in the $4 \%$ wt. surfactant water solution, at the same temperature, by the aid of agitation at 800 $\mathrm{rpm}$ for $5 \mathrm{~min}$. The obtained preemulsion was further treated by probe-type sonicator (Sonics VibraCell, Sonics \& Materials, INC.), at varying time (2, $5,10 \mathrm{~min}$ ) and energy (15 and $35 \mathrm{~W}$ ) of the process (Fig. 2d), and while maintaining the temperature at least $5^{\circ} \mathrm{C}$ above the melting point of the lipids. Subsequently the dispersions were cooled down to room temperature. The composition of the obtained formulations is shown in Table 1.

Particle size analysis. Particle size analysis was performed by dynamic light scattering (DLS), using the Zetasizer Nano ZS Malvern Instrument. Prior to the measurements all samples were diluted using ultra-purified water to generate suitable scattering intensity. DLS yields the hydrodynamic diameter (mean diameter, z-average) and the polydispersity index (PI) as a measure of the particle size distribution. The mean diameter and PI of the investigated samples were obtained by calculating the average of three measurements, at an angle $173^{\circ}$, in 10 $\mathrm{mm}$ diameter disposable plastic polystyrene cells. All the experiments were performed at $25^{\circ} \mathrm{C}$.

Zeta potential analysis. Zeta potential (ZP) of NLC dispersion was determined by the measurement of the electrophoretic mobility, using Malvern Zetasizer Nano ZS (Malvern Instrument, UK). The conversion into the ZP was performed using Helmoltz-Smoluchowski equation. The measurements for each sample were repeated three times.

Morphology analysis. The morphology of lipid nanoparticles was investigated using the JEOL JSM-7500F microscope, working in the transmission mode. For each measurement, the samples were prepared by dispersing a drop of the NLC formulation on a copper grid, which was covered with a carbon film. 


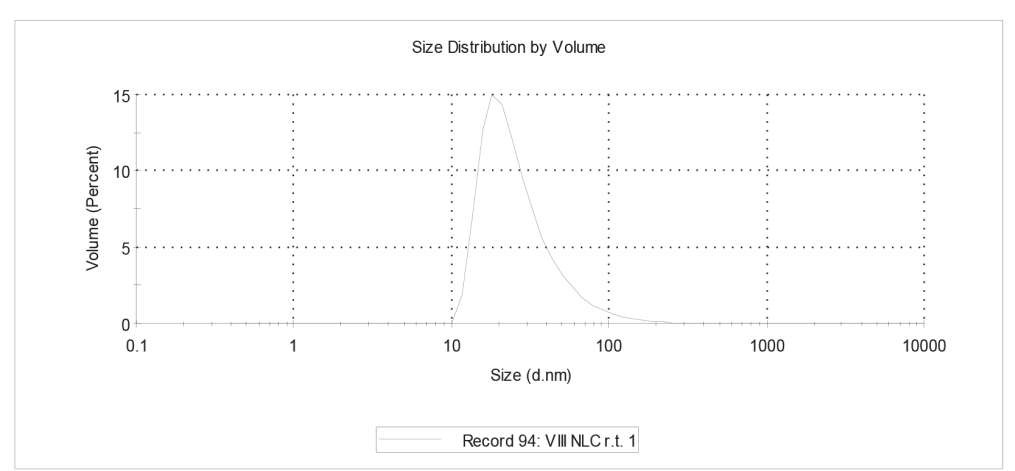

Figure 1. Particle size distribution curves of the optimal formulation (no 1).

\section{RESULT AND DISCUSSION}

\section{Particle size analysis and physical stability}

It is believed that the particle size distribution is one of the most important parameter for the evaluation of the stability of colloidal systems. Figure 1 shows the particle size distribution of the nanoparticulate dispersion. The mean particle size of sample number 1 is $56 \mathrm{~nm}$. This formulation indicated the maximum stability.
Effect of different parameters on a particle size and zeta potential measurement

As a result of comparison of the influence of different lipids on a particle size (Fig. 2A), it has been found that the average particle size of NLC dispersions is the highest for Compritol 888 ATO. This is the solid lipid characterized by a melting point $\left(69-74^{\circ} \mathrm{C}\right)$ much more higher than for other lipids. Moreover PI for this type of lipidic matrix possesses values of 0.367 , which implies polidisperse populations. Typical values for $\mathrm{o} / \mathrm{w}$ emulsions range from 0.1 to 0.25 (Kovacevic et al., 2011). The best size result was obtained for the formulation containing Apifil.

Concerning emulsifiers, the best results were obtained for PlantaCare (alkylopolyglucoside) and its combination with other surfactants (Fig. 2B).

The date presented in Fig. 2C show that particle size increases with the increase of the lipid content, which is in agreement with the other research group (Siekmann et al., 1994). The same situation was observed when solid to liquid lipid ratio increased (Fig. 2C, formulation no 1 and 4).

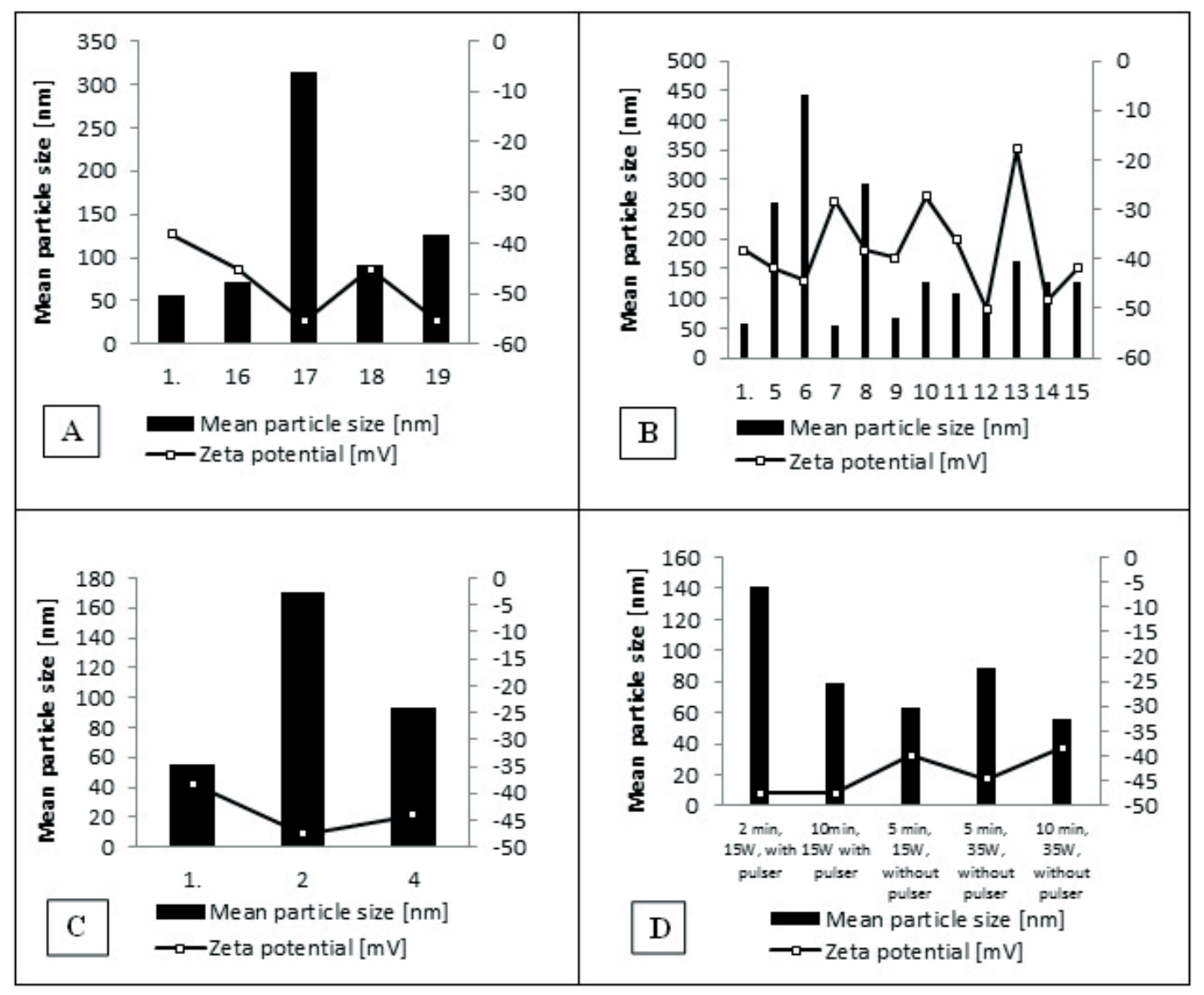

Figure 2. Influence of different parameters on a particle size and zeta potential measurement.

(A) Influence of different lipid (solid and liquid), (B) Influence of emulsifier (single or combination), (C) Influence of solid to liquid lipid ratio, (D) Influence of ultrasound parameters. The number of samples from the figures corresponds to the one from Table 1. 

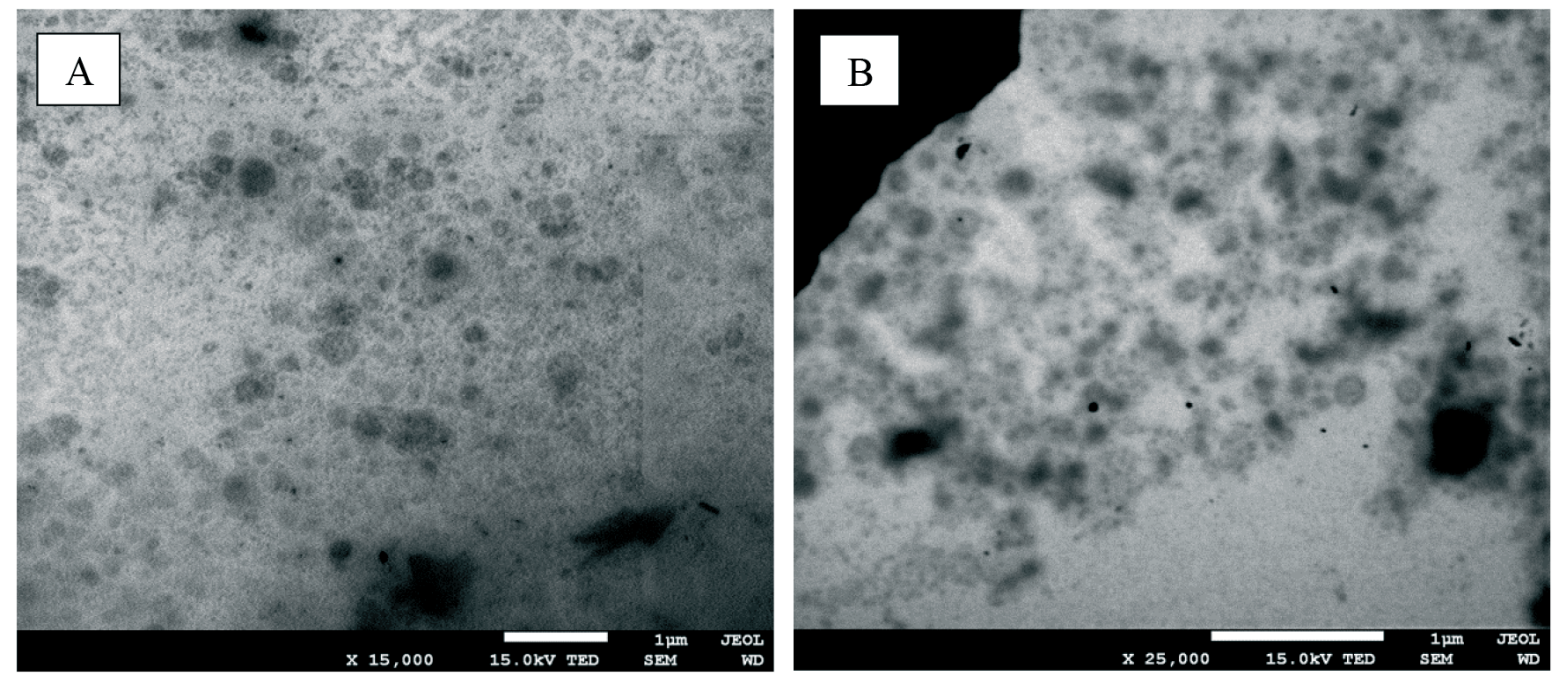

Figure 3. Microphotographs of NLC formulation. A and B represent the views from different positions with different amplification factors (15000 and 25000 respectively).

Ultrasonication parameters, applied to obtain the formulations containing Apifil and Myritol (7:3), dispersed in $4 \%$ wt. PlantaCare solution, influenced the mean particle size. The smallest particle size was achieved by treating the sample with a probe-type sonicator for 10 $\mathrm{min}$ at $35 \mathrm{~W}$ and its value was $56 \mathrm{~nm}$ (Fig. 2D).

Zeta potential is an important factor used to evaluate the stability of lipid nanoparticle dispersions. Generally, particles are stable when the absolute value of the zeta potential is more than $30 \mathrm{mV}$. In our case, for the optimal formulation (no 1) ZP was around $-38 \mathrm{mV}$. This is the formulation with nonionic surfactant, which could not ionize into charging group like ionic, but demonstrated its ZP. The same observation was made by other researchers (Jain et al., 2011). The reason might be molecular polarization and the adsorption of emulsifier molecule on the charge in water. It was absorbed to the emulsifier layer of particle/water interface, and an electric double layer similar to ionic was formed. Even better results of ZP value were also obtained for Poloxamer $188(44.3 \mathrm{mV})$ and its mix with PlantaCare $(-41.9$ $\mathrm{mV}$ ) but the mean particle size of these formulations was too large (263 and $442 \mathrm{~nm}$, respectively). Also good results of ZP value were observed for the system based on the combination of PlantaCare with Tween-80 (-50.1 $\mathrm{mV}$ ), but in the case of the formulation containing only Tween-80, ZP dramatically increased $(17.9 \mathrm{mV})$. On the other hand, nanoparticle dispersion obtained using the combination of PlantaCare as nonionic surfactant with ionic Sodium cholate exhibited not only reasonable ZP values $(48.5 \mathrm{mV})$, but also mean particle size $(120 \mathrm{~nm})$. Unfortunately, in contrast to formulation 1 (chosen as optimal), they were stable for no longer than 2 weeks.

\section{TEM observation}

TEM images of the dried suspension of NLC (no 1) are presented in Fig. 3. The two pictures represent the views from different positions with different amplification factors. Both indicate that the NLC particles are spherical. The diameter is around $60-200 \mathrm{~nm}$. The sample for TEM images was 10\% lipid (solid to liquid 7:3), dispersed in 4\% PlantaCare $^{\circledR}$ aqueous solution. According to the size data based on DLS method, the mean diameter was $56 \mathrm{~nm}$. The size difference obtained by
TEM and DLS may come from the fact that DLS do not "measure" the particle size but detect the light scattering effects, which are used to calculate the particle size. What is more, our NLC formulation, obtained by ultrasonication method, was not a perfect homogenous system (PI 0.237).

\section{CONCLUSION}

The obtained results showed that the composition of preemulsion and the process parameters exert significant influence on the nanoparticles structure. Stable formulation, of particles size approximately 60 to $80 \mathrm{~nm}$, was prepared by ultrasonication of the mixture for 10 min, at $35 \mathrm{~W}$, maintaining the temperature at least $5^{\circ} \mathrm{C}$ above the lipid melting point. APG and its combination showed best results, as a stabilizing agent.

\section{Acknowledgements}

The research (work) was supported by the European Union through the European Social Fund within „Cracow University of Technology development program - top quality teaching for the prospective Polish engineers; University of the 21 st century" project (contract no. UDA-POKL.04.01.01-00-029/10-00).

\section{REFERENCES}

Almeida AJ, Souto E (2007) Solid lipid nanoparticles as a drug delivery system for peptides and proteins. Adv Drug Deliv Rev 59: 478-490.

Chen CC, Tsai TH, Huang ZR, Fang JY (2010) Effects of lipophilic emulsifier on the oral administration of lovastin from nanostructured lipid carriers: Physicochemical characterization and pharmacokinetics. Eur J Pharm Biopharm 74: 474-482.

Das S, Chaudhury A (2011) Recent advances in lipid nanoparticle formulations with solid matrix for oral drug delivery. AAPS Pharm Sci Tech 12: 62-76.

Han F, Li S, Yin R, Liu HZ, Xu L (2008) Effect of surfactant on the formation and characterization of a new type of colloidal drug delivery system: nanostructured lipid carriers. Colloids Surf $A$ 315: 210-216.

Hu FQ, Jiang SP, Du YZ, Yuan H, Ye Y, Zeng S (2006) Preparation and characteristics of monostearin nanostructured lipid carriers. Int J Pharm 314: 83-89. 
Jain NK, Ram A (2011) Development and characterization of nanostructured lipid carriers of oral hypoglycemic agent: selection of surfactants. Int J Pharm Sci Rev Res 7: 125-130.

Kovacevic A, Savic S, Vuleta G, Müller RH, Keck CM (2011) Polyhydroxy surfactants for the formulation of lipid nanoparticles (SLN and NLC): effect on size, physical stability and particle matrix structure. Int J Pharm 406: 163-172.

Müller RH, Mehnert W, Lucks JS, Schwarz C, zur Muhlen A, Weyhers H, Freitas C, Ruhl D (1995) Solid lipid nanoparticles (SLN): an alternative colloidal carrier system for controlled drug delivery. Eur J Pharm Biopharm 41: 62-69.

Müller RH, Petersen RD, Hommoss A, Pardeike J (2007) Nanostructured lipid carriers (NLC) in cosmetic dermal products. Adv Drug Deliv Rev 59: 522-530.

Müller RH, Radtke M, Wissing SA (2002a) Nanostructured lipid matrices for improved microencapsulation of drugs. Int J Pharm 242: 121-128.

Pardeike J, Hommos A, Müller RH (2009) Lipid nanoparticles (SLN, NLC) in cosmetic and pharmaceutical dermal products. Int J Pharm 366: $170-184$.

Radtke M, Souto EB, Müller RH (2005) Nanostructured lipid carriers: a novel generation of solid lipid drug carriers. Pharm Technol Eur 17: 45-50.
Saraf S, Gosh A, Kaur CD, Saraf S (2011a) Novel modified nanosystem based lymphatic targeting. Res J Nanosci Nanotechnol 1: 60-74.

Saraf S, Rathi R, Kaur CD, Saraf S (2011b) Colloidosomes an Advanced Vesicular System in Drug Delivery. Asian I Sci Res 4: 1-15.

Sawant KK, Dodiya SS (2008) Recent advances and patents on solid lipid nanoparticles. Recent Pat Drug Deliv Formulat 2: 120-135.

Schafer-Korting M, Mehnert W, Korting HC (2007) Lipid nanoparticles for improved topical application of drugs for skin diseases. $A d v$ Drug Deliv Rev 59: 427-443.

Schwarz JC, Weixelbaum A, Pagitsch E, Löw M, Resch GP, Valenta C (2012) Nanocarriers for dermal drug delivery: Influence of preparation method, carrier type and rheological properties. Int I Pharm 437: 83-88.

Siekmann B, Westesen K (1994) Melt homogenized solid lipid nanoparticles stabilized by the nonionic surfactant tylaxopol. Preparation and particle size determination. Pharm Pharmacol Lett 3: 194-197.

Westesen K, Bunjes H, Koch MHJ (1997) Physicochemical characterization of lipid nanoparticles and evaluation of their drug loading capacity and sustained release potential. J Control Release 48: 223-236.

Zheng M, Falkeborg M, Zheng Y, Yang T, Xu X (2013) Formulation and characterization of nanostructured lipid carriers containing a mixed lipids core. Colloids Surf A 430: 76-84. 